\title{
The Effect of Mean Platelet Volume on the Patients with Nasal Polyps
}

The Editor,

Sir,

With great eagerness, we have read the study in your journal entitled "Mean platelet volume in nasal polyps" by Aktas et al (1). We would like to make some comments about this study. In recent years, many studies, which state there is a significant relation between the decrease of mean platelet volume (MPV) and inflammatory burden of several diseases, have been published (2-4). Besides this, some studies that search for the relation between nasal polyps and MPV have been reported (1, $5)$. In the results of these studies, there are conflicting comments about the effect of MPV value to nasal polyps. Although a good number of assertive results have been announced in these studies, sufficient usage area of MPV value measurement has not occurred in the follow-up and treatment of patients clinically as there is no fully standardized method of this parameter.

Some of the factors that affect the standardization of MPV measurement are the environment of blood-taking, type and amount of anticoagulant in the blood collection tube, the duration between blood-taking and examination, the device of examination and the calibration time of the device (6). It has been reported that there are measurement differences up to $40 \%$ even among the devices in the studies, in which different devices were used $(7,8)$.

In this study, the fact that the MPV value has been found lower in the patients with nasal polyps in proportion to the control group is agreeable with the literature the information. However, MPV value is a very variable parameter and if we think the lifetime of thrombocyte is between seven and 10 days, this change in MPV expressed at the end of the study may arise from many other factors as waiting for three months for controlled MPV can cause variance to haemogram parameters. While haemoglobin and thrombocyte count values between the control and patient groups were stated in the study, the values of pre-operative and postoperative patient groups and the changes in these values were not stated. Moreover, it is not clear how long the blood samples were taken from test subjects stayed in the tube with ethylenediamine tetraacetic acid (EDTA) and when the blood count was made. At the same time, the patients chosen for the study were well excluded in terms of cardiac disease and it is not easy to say that cardiovascular disease risk will decrease in three months in this case group that has essentially no cardiovascular disease risk.
As a consequence, even if MPV has been associated with many illnesses recently, it does not seem possible to evaluate these results with inflammatory diseases in the limited studies state that MPV value is decreased in the patients with nasal polyps. In order to make better comments about this issue, we think that different and prospective studies should be done and the long-term follow-up results of these cases evaluated.

Keywords: Inflammatory diseases, mean platelet volume, nasal polyps, thrombocyte

O Erdur ${ }^{1}, M$ Sereflican ${ }^{2}, V$ Yurttas $^{2}$, F Erdem $^{3}$ From: ' Department of Otorhinolaryngology, Selçuk University, Faculty of Medicine, ${ }^{2}$ Department of Otorhinolaryngology, Abant Izzet Baysal University, Faculty of Medicine, and ${ }^{3}$ Department of Cardiology, Abant Izzet Baysal University, Faculty of Medicine, Bolu, Turkey.

Correspondence: Dr O Erdur, Selcuk University Alaeddin Keykubad Kampüsü 42075 Konya, Turkey.

Fax:+90 33224160 65,e-mail:dromer-dur@yahoo.com

\section{REFERENCES}

1. Aktas G, Sit M, Tekce H, Alcelik A, Savli H, Simsek T et al. Mean platelet volume in nasal polyps. West Indian Med J 2013; 62: 515-8.

2. Polinska B, Matowicka-Kama J, Kemona H. Assessment of the influence of the inflammatory process on the activation of blood platelets and morphological parameters in patients with ulcerative colitis (colitis ulcerosa). Folia Histochem Cytobiol 2011; 49: 119-24.

3. Kapsoritakis AN, Koukourakis MI, Sfiridaki A, Potamianos SP, Kosmadaki MG, Koutroubakis IE et al. Mean platelet volume: a useful marker of inflammatory bowel disease activity. Am J Gastro 2001; 96: $776-81$.

4. Yuksel O, Helvaci K, Basar O, Koklu S, Caner S, Helvaci N et al. An overlooked indicator of disease activity in ulcerative colitis: mean platelet volume. Platelets 2009; 20: $277-81$.

5. Sagit M, Cetinkaya S, Dogan M, Bayram A, Vurdem UE, Somdas MA. Mean plateletolume in patients with nasal polyposis. B-ENT 2012; 8: 269-72.

6. Vizioli L, Muscari S, Muscari A. The relationship of mean platelet volume with the risk and prognosis of cardiovascular diseases. Int J Clin Pract 2009; 63: 1509-15.

7. Lancé MD, Sloep M, Henskens YM, Marcus MA. Mean platelet volume as a diagnostic marker for cardiovascular disease: drawbacks of preanalytical conditions and measuring techniques. Clin Appl Thromb Hemost 2012; 18: 561-8.

8. Jackson SR, Carter JM. Platelet volume: laboratory measurement and clinical application. Blood Rev 1993; 7: 104-13. 